\title{
El aborto
}

\section{Lidia Casas ${ }^{1}$}

El aborto no resulta una cuestión de meras posturas ideológicas o políticas sino de profundas experiencias humanas. Se trata de hablar de la justicia o injusticia de la continuación de un embarazo cuando no se quiere o no se puede. No es cualquier vivencia sino que una que tiene muchas y diferentes significaciones, pues el contexto es todo.

El acercamiento a esta experiencia humana me la dio la posibilidad de escuchar relatos de la decisión de una amiga adolescente, sin que yo pudiera comprender la magnitud de su decisión, entendía que debía estar allí, aunque no fuera un gran aporte.

Pero solo después cuando las mujeres de mi propia familia, que no hablan desde el lenguaje del control del propio cuerpo, sino con narraciones simples en que contaron las experiencias límites del enfrentamiento en la decisión de someterse al remedio que nadie sabía si sería peor que la enfermedad. Tampoco era una negación de las implicancias morales de la decisión, sino más aún eran todas las circunstancias sopesadas y valoradas por esas mujeres.

No cabía en su repertorio la expresión matar, asesinar, sino la voz remediar y para ellas fue con un dolor físico intenso, en ocasiones con graves secuelas. Pocas veces supe o escuché de ese otro dolor al que se refieren aquellos que abogan por la penalización e insisten en mostrar: el del trauma que siembran en la mente de mujeres. Eso no es otra cosa que la instalación del miedo, es la exposición a una especie de fatídico castigo que vendrá de la divinidad.

Pero también escuché y vi de cerca el aborto donde era legal, en una ciudad donde se escucha el ruido de la nieve y las mujeres -la mayor parte de las veces- solas, están a la espera, debajo de sábanas blancas y limpias, algunas lloran y otras no. Vi y acompañé a mi amiga refugiada salvadoreña que en el último momento optó por tener su hijo, y lo importante que fue que ella tomara su decisión y nadie más por ella. 
Mi mirada al aborto creció intuitivamente en lo que podemos llamar justicia de género que describe Bascuñán en la constatación de que las cargas no se encuentran distribuidas igualmente entre los sexos. Así, mi incursión entre derecho y aborto fue construido desde el relato vivencial, pues comprender a cabalidad la significación del derecho en la vida de las mujeres es escucharnos a nosotras mismas.

Esta impronta que busca mirar las normas jurídicas no como entes abstractos sino con las repercusiones sociales y políticas concretas, me llevó a escuchar a otras, las que la pasaron más mal, las que conocieron la ley, el castigo y el estigma social por la decisión que tomaron. Constaté como el sistema tenía una función colateral, asegurar que padecieran el trauma, el dolor, si es que no lo mostraban. Algunas de ellas se enfrentaron a la manipulación debiendo observar obligadamente mientras estaban privadas de libertad aquellos videos antiaborto del Grito Silencioso o fueron enviadas a trabajos para que tomaran conciencia de la maternidad, como si no lo hubieran hecho.

La clase y el género se encuentran naturalmente imbricados en esas narraciones, pero también he constatado que las otras, las que tienen más recursos y privilegios sociales también la pasan mal. En los últimos años, algunas de ellas también han conocido el peso del sistema que, la mayor parte del tiempo, es ejercido más duramente sobre las mujeres pobres de nuestra sociedad.

La posibilidad de cambiar la vida de nosotras se convierte en una tarea más ardua, cuando ha crecido, al menos en el volumen de las voces, esa necesidad de controlar y reprimir.

Pero también aprecio algunos cambios en círculos pequeños académicos y políticos. Hace unos cinco años atrás presencié el lanzamiento de una revista de derecho en que se comentaba un artículo de Antonio Bascuñán. El comentarista señaló que Bascuñán se había equivocado en seguir una discusión en torno al aborto cercano al feminismo, ya que sus argumentos, a pesar de lo erudito del texto y el análisis de la dogmática constitucional y penal, no lograba persuadir al comentarista sobre la idea de que existieran razones supralegales para permitir el aborto en Chile. La idea de que la mujer es la que experimenta la maternidad y por ello, el Estado debe, al menos, asegurar que bajo ciertos supuestos ella pueda terminar con el embarazo no constituyó una buena razón para aceptar esa tesis. Nuestro comentarista refutó 
señalando que la dogmática, es decir, el estricto y abstracto estudio del Derecho, no estaba acompañado de elementos fácticos que pudieran convencerlo sobre los efectos de la penalización del aborto y de la necesidad de contar con herramientas que permitan el aborto por indicación. Ese comentarista hoy aboga por una discusión por la despenalización del aborto terapéutico.

La decisión de terminar con un embarazo no es una decisión amoral, y ello porque socialmente valoramos la vida en sus diversas manifestaciones. Pero esa elección, es ante todo, una manifestación de un fuerte conflicto sobre el cual la sociedad debe considerar, en primer término, la condición de sujeto de la mujer.

\section{Nota}

1 Profesora e investigadora de la Facultad de Derecho de la Universidad Diego Portales. 